specific diarrheal syndrome. These are children with a massive overgrowth of anaerobic bacteria in the upper small bowel. They excrete relatively small amounts of unchanged neutral lipids and small amounts of primary bile acids in the feces because of increased bacterial action.

It would be interesting to know to what extent a modified bacterial flora affects cholesterol or sterol balance. In addition to the well known relationship between diet and blood cholesterol levels, other factors may come into play. Normal people in differing countries have a wide range of intestinal function. The
D-xylose absorption and fat absorption tests have different ranges of normal values. It would be interesting to know whether increases in bacterial flora are playing a role in the lower blood cholesterols seen in patients in developing areas where sanitation is, in general, very much poorer than in North America. $D V$, for instance, represents the extreme of sanitation. Studies by Kellogg (27) indicate that in rats in a germ-free environment, hepatic cholesterol and blood cholesterol are increased. The serum cholesterol value in $D V$ is low, but this undoubtedly is a reflection of his extremely low cholesterol intake.

\title{
VII. Mental, Psychomotor, and Psychosocial Development
}

\author{
BARRY MOLISH, MARY MURPHY, AND MURDINA DESMOND
}

The Department of Pediatrics, Baylor College of Medicine, The Leopold Meyer Center for Developmental Pediatrics, Texas Children's Hospital, Houston, Texas, USA

The following data are based upon observation of $D V$ 's behavior as well as on the results of standardized developmental schedules and intelligence scales. They reflect his ability and achievements as accurately as possible within the limitations imposed by his unique environment on the testing procedures, such as the necessity for sterilization and modification of some of the test items.

\section{INITIAL EVALUATION}

The initial evaluation was on March 15, 1972 when he was 5 months, 24 days of age. The Bayley Scales of Infant Development (6) were selected to obtain a baseline measure for reference in assessing his future longitudinal course of development. The findings were: Mental Scale Index: 116 (6.5-7.5 months); Psychomotor Scale Index: 112 (6.5-7.5 months).

On the Mental Scale Index this child was approximately 1 month above his age level. This was probably an underestimate because of four items scored as "omitted" because of difficulty in administration. Basal Age (level of consistent success of 10 consecutive passes) was established as 5.7 months. Ceiling Age (highest level of success before 10 consecutive failures) was 8.9 months. Items passed included: transfers object hand to hand, 5.5 months; lifts cup with handle, 5.8 months; looks for fallen spoon, 6.0 months; playful response to mirror, 6.2 months; manipulates bell -interest in detail, 6.5 months; rings bell purposively, 7.8 months; fingers holes in pegboard, 8.9 months. Items failed included: interest in sound production, 5.8 months; attends to scribbling, 5.8 months; vocalizes four different syllables, 7.0 months; attempts to secure three cubes, 7.6 months; listens selectively to familiar words, 7.9 months; says "da-da" or equivalent, 7.9 months.

The child's interest in sound production and his response to sound was slightly below the level of his overall mental development. The plastic barrier does slightly diminish the transmission of sound.

On the Motor Scale, Basal Age was 6.6 whereas Ceiling Age was 7.1 months. Items passed included: rotates wrist, 5.7 months; sits alone thirty seconds or more, 6.0 months; rolls from back to stomach, 6.4 months; sits alone steadily, 6.6 months; sits alone good coordination, 6.9 months; prewalking progession, 7.1 months. Items failed included: scoops pellet, 6.8 months; early stepping movements, 7.4 months; pulls to standing position, 8.1 months; raises self to sitting position, 8.3 months.

The test findings indicated that, on average, he was at least a month advanced in both mental and motor development.

\section{FOLLOW-UP EVALUATION}

The second evaluation, done on September 9, 1974 at age 3 years, 4 days, was made when he was in his isolator at home with his mother present. The Stanford-Binet (50) test items in Table 1 afford a cross-section of his intellectual development.

It was possible to administer only one test item at Year V (Definitions), and he passed this.

The high level of success in the Discrimination of Forms Test at Year Level IV is especially noteworthy. He identified all 10 geometric figures and at times correctly named them. This indicated unusual ability in determining size and shape of objects. This type of perceptual skill could be related to the environment he lives in, where the geometry of all the mechanical aspects of his isolation chamber has an enhanced valence for him and certainly would influence his entire framework of object relations.

His general language skills, measured by the McCarthy Scales (34), were within the 4-year, 6-month to 5-year level. 
Table 1. Results of Stanford-Binet test given at age 3 years to child raised in isolation

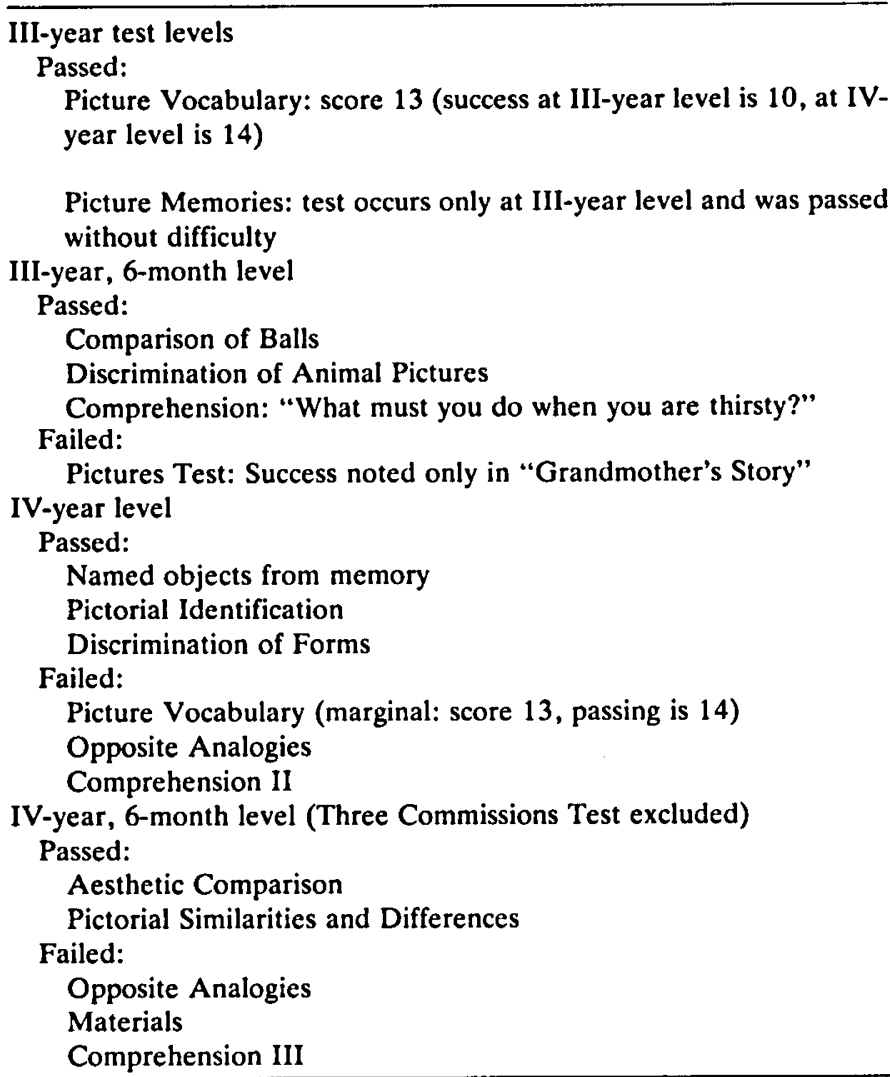

A cross-sectional measure of his potential intellectual endowment was estimated to be within the 4-5 year age range. This was 1-2 years above his actual chronologic age of 3 years.

To obtain some evaluation of his general ego functioning and overall level of psychosocial adaptation, the Rorschach Test (45) and the Children's Apperception Test $(\mathrm{H})(7)$ were administered.

Table 2 shows his verbatim Rorschach responses. Some findings were quite interesting. His recognition of the popular human figure forms in Cards II and III was considered an asset. His ability to organize the details of Card II into a fantasy response of "two men clapping hands" was also of special note. The perseveration noted in the "tree" response at this time could not objectively be regarded as an ego loss in his concept formation. His rejection of the usual popular responses in Cards I, III, V, and VIII was recognized. These were attributed to the limitations in his background of experience. There was a healthy awareness of the color nuances in Cards IX and X.

The level of his productivity was rather low considering his age level and his above average intellectual potential. This was considered to be a reflection of the unusual structure of his social opportunities. The tests show, however, that there was no apparent idiosyncratic or dereistic quality in his ideation or concept formation.

In the Children's Apperception Test $(\mathrm{H})$, his overall response to the 10 cards was nominal. His responses were primarily descriptive with no effort made to relate the figures of the cards to any type of interaction. This finding was not surprising, since the social situations involved in each of the cards are foreign to his real life environment.

The Minnesota Child Development Inventory (MCDI) (24) is based upon the parent's ratings of various developmental behavioral items which they rated independently of each other in order

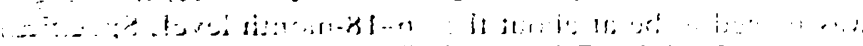
Copyright $\odot 1977$ International Pediatric Research Foundation, Inc.
Table 2. Verbatim Rorschach responses of 3-year-old child raised in isolation

Card I

1. "Airplane" (whole response)

2. "Triangle" (The small white space detail. Of special interest in view of his keen awareness of geometrical forms described in the Stanford-Binet findings.)

Card II

1. "Is that a picture of a man? Two men clapping hands." (usual popular human figures)

Card III

1. "Airplane" (vague whole)

Card IV

1. "Tree-just a tree" (whole)

Card V

1. "Airplane" (whole)

Card VI

1. "A tree" (whole)

Card VII

1. "Babies-picture of a baby's face." (usual, popular human figure detail)

Card VIII

1. "What is that . . a tree?" (whole)

Card IX

1. "Pretty-looks like a tree." (whole)

Card X

1. "Yellow, blue, brown." (color naming)

2. "Looks like a tree." (? whole)

3. "Pencil on top." (top detail)

Table 3. Parents' ratings of developmental behavioral items (Minnesota Child Development Inventory (MCDI)), at age 3 years of child raised in isolation

\begin{tabular}{lcc}
\hline & \multicolumn{2}{c}{ Age placement } \\
\cline { 2 - 3 } \multicolumn{1}{c}{ Scale } & Mother & Father \\
\hline General Development & 3.3 & 3.2 \\
Gross Motor & 2.6 & 2.9 \\
Fine Motor & 2.9 & 2.9 \\
Expressive Language & 4.0 & 4.0 \\
Comprehension-Conceptual & 4.3 & 4.2 \\
Situation-Comprehension & 2.2 & 2.6 \\
Self-Help & 2.8 & 2.8 \\
Personal-Social & 3.0 & 3.0 \\
\hline
\end{tabular}

to determine the consistency with which they rated his level of development. The results are shown in Table 3.

The ratings by the parents coincided in virtually all areas. In the scales in which $D V$ was rated below his age level, the behavioral items were not applicable in view of his atypical environment and the fact that he has not had the opportunity for these kinds of experiences.

\section{ADDITIONAL COMMENTS AND OBSERVATIONS OF BEHAVIOR AT AGE 3 YEARS}

This was a delightful, appealing child who responded appropriately to the examiner. He was aware of success and failure as related to test questions; e.g., at items for the 6-year level on the Stanford-Binet he would say, " $D V$ doesn't remember" or "Don't remember $-D V)$." At other times, when materials presented were too difficult, he would jump up and down or ask to see other pictures. (The latter is typical test behavior for children at 3-5 years.) This child was manipulative and constantly tried to control the situation. 